\title{
I like your image. Políticas da afetividade e da cultura de arquivo na rede
}

\author{
REMEDIOS ZAFRA
}

\section{Resumo}

A cultura-rede é um cenário marcado pela convivencia e construção de mundo e subjetividade por meio das telas dos aparatos tecnológicos, num contexto em que prevalece o visual. Na cultura-rede configuram-se novos habitats de relação, de onde se desdobram condicionantes biopolíticos para ser e poder ser. Considerando as contradições

Palavras-chave: Cultura-rede, afetividade, cultura de arquivo, visual emergentes, destaca-se o tempo atual como um período de reflexão e mutação dos vínculos afetivos e políticos, na direção da construção coletiva do comum e do que importa. 


\section{I like your image. Affectivity and file culture policies in the net}

\begin{abstract}
Net-culture is a scenario marked by common life and by the construction of world and subjectivity through technological screens, in a landscape where prevails the visual. In net-culture, new habitats of relation take form, generating the bio-political conditions in order to be and to can be. Considering the emerging contradictions, it is necessary to emphasize that this is a time to this is a time of reflection and mutation of affective and political relations, in order to produce colective constructions of what is common and what matters.
\end{abstract}

Keywords:

Net-culture, affectivity, file culture, visual 


\title{
I like your image. Políticas de la afectivi- dad y cultura de archivo en la red
}

\author{
REMEDIOS ZAFRA
}

\section{Resumen}

Cultura-red es un escenario definido por la convivencia y construcción de mundo y subjetividad a través de las pantallas en un contexto excedentario en lo visual. En la cultura-red se configuran nuevos hábitats de relación de los que se deducen condicionantes biopolíticos para ser y para poder ser. Teniendo en cuenta que las contradicciones perviven, cabe

Palabras-clave: Cultura-red, afectividad, cultura de archivo, visual tolerar el tiempo que vivimos como un periodo de reflexión y mutación de los vínculos afectivos y políticos rumbo a la construcción colectiva de lo común y de lo que importa. 


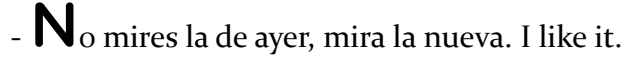

- I love you. Mira las mías. I like it. I like it. I like it. ${ }^{1}$

Laura Bey

(P)ertenece a la categoría del to like y no del to love; moviliza un deseo a medias, un querer a medias; es el mismo tipo de interés vago, liso, irresponsable, que se tiene por personas, espectáculos, vestidos o libros que encontramos "bien". Roland Barthes

Lo parece. Parece que habitamos una época grandeen la potencia de sus nuevas formas de compartiry construir, y no menos poderosa en la amenaza de fragilidad y en las formas de desigualdad y crisis que la acompañan. Habitamos, entonces, un comienzo, donde hay zonas de contraste que atraen y asustan porque son desconocidas o porque están gestándose y, justamente por ello, nos implican como agentes activos; zonas que no quieren convertirse en copias de los grandes caminos ya transitados.

Este escenario, al que en estas reflexiones llamaré cultura-red, viene definido por la convivencia y construcción de mundo y subjetividad a través de las pantallas en un contexto excedentario en lo visual (imagen, información, datos...). Contexto caracterizado en un marco donde conviven formas de capitalismo cognitivo o informacional con otras formas de economía social que surgen desde la ciudadanía. Allí donde podemos gestionar trabajos, afectos, conocimiento y vida ayudados (o condicionados) por las lógicas algorítmicas y de bases de datos que alimentamos y que nos alimentan online, organizando visibilidad y existencia. Pero esta cultura-red no sólo proporciona mecanismos para lo que hoy consideramos imprescindible en una sociedad global y conectada, sino que gestiona lo excedentario, lo acumulado que se manifiesta en 
lo social y en lo individual, el sobrante de cosas digitales que crecen exponencialmente y que diariamente producimos, consumimos y desechamos de los otros, permitiéndonos nuevos hábitats de relación de los que se deducen condicionantes biopolíticos para ser y para poder ser, nuevas manifestaciones de la realidad social y del poder en la red.

Un asunto prioritario aquí sería el que relaciona ser visto en la pantalla con existir para el mundo (nuestro mundo) y formar parte de las nuevas lógicas de "valor" en contexto. Con independencia incluso de una existencia material, lo expuesto y enmarcado en la pantalla, sea representado, presentado o creado, es lo que parece determinar hoy la nueva ontología de la cultura-red, la nueva articulación de lo real.

Claro que interesará de manera más intensa aquello que existiendo en la red alude a la materialidad de un sujeto, aquello que recorre la complejidad del habitar hoy de las personas un mundo irreversiblemente conectado. Porque lo que se deduce de esta configuración de colectividades de individuos que se comunican, observan e intercambian frente a sus diversos dispositivos móviles, habla de un territorio peculiar para entender las formas de economía y política que vienen. En ellas se alza una práctica cotidiana, habituarnos a la autogestión del excedente de cosas que compartimos y que nos comprometen a través de lo que vemos.

Entender la (posible) obligatoriedad de dicha práctica, o por qué muchos la perciben como tal, implica facilitar la toma de conciencia del ver y sus repercusiones afectivas, sociales y políticas en las redes. Me refiero a la conciencia no sólo como "saber y conocimiento" de afuera, sino también como gozo, descubrimiento, epifanía del uno mismo, mirada interior, liberación de la dependencia frente a lo que vemos.

$\mathrm{Si}$ el capitalismo se ha basado de manera indispensable en el doble dispositivo "disciplina y gestión"3 como órdenes de funcionamiento y control, cabría identificar de qué manera, en qué contextos, este doble código sigue operando en la cultura-red. De la misma forma, que habríamos de conocer dónde y cómo está siendo difuminado. Es decir, dónde la red adquiere un potencial más transformador frente a la disciplina y la gestión capitalistas. Considero que esas ubicaciones tienen que ver con las zonas en las que viejas parejas que marcaban relaciones dicotómicas como: conocido-extraño, público-privado, afición-trabajo o producción-consumo, están siendo transgredidas hacia un nuevo modelo articulado sobre lazos afectivamente ligeros con muchos que nos obligan sutilmen- 
te; dando forma a un escenario que difiere muy claramente del mundo pre-Internet.

\section{Cultura visual excedentaria: poder y archivo}

Muchas cosas en nuestros días se nos hacen hoy imprescindibles. Algunas porque desde siempre las necesitamos, otras porque comenzaron siendo accesorias y ahora nos angustiamos al pensar vivir sin ellas. Es a estas últimas a las que quiero referirme, pues considero que una sociedad digital y de consumo como la nuestra opera como una sociedad de excedente, donde abundan por definición cosas prescindibles, como esas ingentes bases de datos de fotografías propias y tweets que nos preceden y conforman las nuevas formas de biografía. Una biografía que importa en el instante (ahora) donde se comparte archivo y que mañana será olvidada, aunque en conjunto o descontextualizada en búsquedas perviva y signifique para quien mire.

Es el sobrante lo que se convierte en producto o servicio cuyo reto comercial aspira a configurarlo como necesidad. Y si algo define la cultura-red como cultura visual contemporánea sería su carácter excedentario. El inconmensurable mundo de imágenes que marca esta época forma parte del excedente que se ha ido conformando como nuevo ecosistema de ojos frente a las pantallas. Un sobrante que sentimos que nos arropa y acompaña de manera incondicional. De él salimos y entramos siempre que tengamos un dispositivo electrónico cerca, demandándonos (suavemente) sucumbir a la comunicación, juego o interacción sostenida con los otros. Algo que podríamos no aceptar, pero que finalmente buscamos, incluso con cierta obsesión (esa otra forma de necesitar). Sucumbiendo a la comunicación afectiva que es buscada por la lógica del dispositivo en cuestión. Desde la convicción de que los afectos positivos promueven la comunicación y el conflicto o el disentimiento lo paralizan.

La imagen como excedente circula como presencia en apariencia inútil, pero en tanto normalizada forma parte de los rituales cotidianos. De ellos se valen además los imaginarios para construir aparato identitario. Una cuestión clave atendiendo a cómo la cultura-red se conforma de imágenes, información y contextos, sería advertir que si estos excedentes son útiles es por ser elegibles, pero que esto es sólo una apreciación primera, una suerte de ensueño, un delirio de libertad dificultada. Todo lo que se vuelve opcional y juego, genera la sensación de que es voluntario primero, provocando después 
la ansiedad del deseo. El hábito de lo prescindible en la cultura visual y digital culmina a menudo como algo que muchas personas necesitan (por ejemplo, conectarse a cada rato, actualizar su perfil varias veces al día, dedicar los tiempos de tránsito a jugar o a conversar... buscar, buscar, abrir y cerrar, revisar compulsivamente por si algo se hubiera perdido, por si algo cambiara o mejorara nuestro monótono día, demandándonos la incondicionalidad online de un 24 horas). Mi impresión es que justamente su carácter a priori prescindible y excedentario es lo que más fascina, es lo que seduce. Quiero decir que ninguna de las aplicaciones y usos a los que me refiero se nos presentan como imprescindibles pero terminan convirtiéndose en necesarios, porque de alguna manera contribuyen a regular (o a alimentar, no está claro) la "ansiedad" contemporánea de vivir permanentemente conectados.

En algún momento de nuestra historia reciente pasamos por alto que la elección era ya vivida como exigencia, que difícilmente una vida comprometida con la época, podía mantenerse al margen y obviar la inmersión inclusiva y socializadora en el universo de imagen construida tecnológicamente como parte de la cultura-red contemporánea. La tecnología ha acelerado primero la estetización derivada de la extrema visualidad facticia y luego la inmersión normalizadora.

Antes, hubo historias de los ojos y el poder, historias cuyas imágenes sagradas y veneradas representaban un poder y un sistema; más tarde, hubo historias de las imágenes y el capital, ese otro poder que aún perdura, reforzado. Pero la conversión de gran parte de nuestros mundos de vida en mundos estetizados, conformados por imágenes creadas y/o mediadas por pantallas es algo nuevo, algo que sin duda habla de una necesaria transformación del ser humano. Si hubo épocas en las que los humanos debieron acostumbrarse a otros climas y a cambios materiales en sus hábitat, hoy la época nos demanda vivir en un mundo excesivo en las representaciones y, como en una mutación hiperbolizada del espejo, entre las representaciones de nosotros mismos.

No obstante, observen cómo el valor añadido derivado de establecer un grado de equivalencia entre ojos y capital logra en el posicionamiento el canal que le permite asentar dicha equivalencia. Es decir que la gestión de la visibilidad (no reducida a un producto o servicio sino disuelta en cada interacción en la cultura-red) sería objeto de negociación y valor de cambio en constante alza, bajo el poder (siempre simbólico, pero potencialmente también material y especulativo) que otorga 
"ser" visto. Ocurre entonces que los intereses puestos en lo que hacemos circular en las redes convierten el excedente en algo singularmente rentable. De esta manera, la gestión de la visibilidad y del posicionamiento no pueden ser ya solamente cosa del Marketing o de la Publicidad, ni siquiera de la Estadística o la Sociología, pues los sujetos y las vidas se entrelazan en lo que está en juego. Y como respuesta surge la reclamación de una urgente y necesaria lectura política y crítica de la cultura-red, una lectura capaz de deconstruir y enfrentarse a las nuevas lógicas de valor que estamos construyendo mediante una cultura digital excedentaria en lo visual y en la autorepresentación.

\section{La vida (fotografiada) al lado de nosotros mismos: vanidad y afectos}

(...) a lo sumo puedo decir que en ciertas fotos me soporto, o no, según si me encuentro conforme a la imagen que quisiera dar de mí mismo. ${ }^{4}$

Roland Barthes

Podría estar horas observando las fotos de mis conocidos en Internet. Me fascina (o me asusta, no lo tengo claro) el afán por acumular y compartir decenas, cientos o miles de fotos en sus respectivas redes sociales destinadas a este fin (compartir imágenes de sí mismos). Entre otras cosas, me resulta llamativo advertir cómo esas fotos aumentan pero rara vez desaparecen, es decir siempre crecen. Y lo pienso mientras afuera llueve y la ventana me deja ver algunas nubes que se mueven. Y pienso en las nubes y en los charcos que en un segundo cambian, frente a estas redes que cambian pero no menguan, donde "todo" se archiva e incrementa,, aunque mañana no lo veamos. Como si lo digital pudiera ser infinito y no tuviera límite ni medida en su afán de crecimiento y acumulación.

Me llamó la atención la foto de una chica junto a un personaje popular de televisión. La compartía en Facebook, Instagram y Twitter. Presumía de ella como una imagen que con seguridad le haría conseguir muchos "me gusta" y "re-tweets". Me preguntaba cómo frente a la visibilidad reducida de los fetiches de antes limitados a las visitas de amigos y familiares, esta foto aspiraba a incrementar su valor siendo muy vista. Los clásicos fetichistas encontraban el placer en lograr un objeto de su ídolo, un libro convertido en infraleve porque fue tocado por él, o una foto de edición limitada; o mejor, una 
prenda con algo de aura, de tacto o de olor, de la persona a la que se admira o se desea... Para la chica sin embargo la foto ni siquiera tendrá un lugar especial en un cajón digital que la proteja, será expuesta allí donde pueda lograr más miradas. Desmaterializada y sin aura, lo que aquí más importaba es que sus amigos y conocidos la vieran.

La foto tan forzada que casi parecía un montaje o que tal vez lo fuera, forma parte de la infinita carpeta de imágenes propias de muchos álbumes online. El autorretrato como lo inevitable. Y como variante posible, el autorretrato que incorpora al otro más famoso que uno. Lo que pareciera un valor añadido, un plus de inversión para ser más visto, para aumentar el interés y el valor de la posesión de miles de instantáneas propias como fragmentos de una vida condicionada por la cámara. Una vida al lado de nuestras imágenes cuyo juego exige la incondicionalidad de la actualización como alimento y vida de la criatura (ese voraz excedente de fotos propias que nunca se satisface y siempre pide más).

"Mirad con quién estoy", "mirad qué hago", "mirad quién es mi amigo"... Y me resulta inevitable relacionar esta tipología de autorretrato con famoso en la cotidiana orgía visual sobre "uno mismo" en las redes, con lo que acontece todavía en espacios como Madame Tussauds, el famoso museo de cera londinense que antes de Internet podría ser considerado uno de los grandes templos del autorretrato de finales de siglo. Una verdadera iglesia de los Estudios Visuales, un fabuloso homenaje al valor impostado en el autorretrato por la fama de la imagen despojada del famoso; es decir, por la foto junto al famoso falso, como falsa es la escena que parece retratarnos junto a un retrato. ¿Qué sino "retrato" es ese muñeco hiperreal y congelado que se deja abrazar y mirar de cerca? La verdad de lo que no se ve es aquí nuevamente la potencia de lo inventado, un aura materializada en objeto que pide ser fotografiado. Porque esas réplicas están ahí no para que las veas sino para que te fotografíes con ellas, para crear imagen de realidad en el trampantojo donde "tú" debes estar. Primero celebrando la escenificación de la mentira hiperrealista, luego jugando con ella y con su ilusión de verdad compartida con quienes deben ser testigos y corroborar lo visto: "Mira con quién he estado", culminando un ejercicio socializador cada vez más mediado por imágenes que oscilan e interseccionan los límites de lo real, lo simbólico y lo imaginario.

Para cada cual el valor de una fotografía depende de nuestra inclusión en dicha imagen, de si nosotros "hemos salido en ella". Estar nos obliga como nos obliga la imagen ante los otros. 
Pero me parece que el gesto de normalización de nuestra vida al lado de nuestras imágenes y fragmentos no contribuye sino a asentar la construcción de un nuevo ecosistema para el sujeto.

Ese ecosistema exige tanto del ver como del "ser visto" en Internet. Tal que en el mismo acto de visibilidad entusiasma y satisface sentir que los otros verdaderamente "nos ven". Un existir como prevalecer, propio de una ontología mediada por la máquina y los ojos. Un sentirnos vivos estando conectados como forma de ser y en muchos casos como búsqueda de "reconocimiento" que funcionará como posible estrato de influencia, trabajo, afecto o, cuando menos, como tierno alimento para la vanidad de un día.

Porque rara vez olvidamos que ser visto "hoy" no garantiza ser visto "mañana". Quizá por ello no importe tanto lo que de nosotros ha sido visto (esa foto o ese famoso al que nos encaramamos), sino que la máquina registre los ojos que nos han mirado. Es decir, que haya evidencia y huella de que no hemos sido indiferentes y que el tiempo caduco de su visibilidad entre el exceso ha sido amortizado con ojos. La garantía de seguir estando la marca la intensidad de esta nueva necesidad que palpita en los conectados: que quede constancia, aunque sea mínima, de nuestra existencia, que un número corrobore que nos han mirado. Después, seguir siendo vistos, como una lucha en apariencia banal pero en la irreflexiva inercia vital, importante; conscientes de la disolución y caducidad con que la máquina tratará nuestros fragmentos mañana, en la inmensidad de datos que se apartan y empujan queriendo lograr ojos y con suerte, algo más de memoria; conscientes de que hoy es el exceso de imágenes lo que funciona como eficaz forma de censura y desaparición.

Pero en Internet, no serían solamente las imágenes propias las que hablarían de una vida al lado de nuestras representaciones. Toda mirada potencial es ahora también tecnológica y posee la capacidad de hacer memoria con nuestros rastros y archivos. Aquí nuestras huellas online pueden adquirir formas cada vez más diversas, no sólo fotografías o fragmentos de vídeos en los que, bien casualmente, bien como parte de una fiesta de cumpleaños, un seminario, una reunión de amigos, o una broma, alguien nos coloca en la red. O también un registro del ayuntamiento, una denuncia, la muerte de una persona con nuestro mismo nombre, una petición de búsqueda de antiguos compañeros de estudios, un elogio, o un insulto en un blog personal... Desde el momento en que esto se publica en la red, se cose algorítmicamente al listado de lo que Google (o buscado- 
res por venir) dicen de nosotros (y performativamente, parecen "crear" sobre nosotros). Es decir, a la parte de la ecuación que el buscador propone cuando preguntamos por nuestro nombre (esa otra imagen del "yo"). Como fragmento de un conjunto -nunca cerrado, nunca estático- que pasará a formar parte del collage de registros colectivos que identifican nuestros nombres en el ciberespacio y al que probablemente los nuevos humanos se habituarán como deriva con el ecosistema, aunque todavía nos inquiete y, en ocasiones, duela.

Y pareciera contradictorio pero forma parte de lo mismo. Que en cada búsqueda demandemos más de nosotros y siempre queramos saber más de los otros, pero que simultáneamente nos duela vernos y queramos también desaparecer (cuando nos descubrimos congelados en el archivo de nuestro peor momento o cansados de habitar mil líneas de fuga). Porque en la entropía que percibimos en el cambio social en la cultura-red nos acostumbramos y no nos acostumbramos al mismo tiempo. Porque sabemos que el exceso de datos no afecta tanto al sujeto como el exceso de imágenes de "sí mismo".

Para muchos, esta presencia no interfiere más allá de la satisfacción de "estar" y el divertimento de "verse" y habituarse a un nuevo estatuto de la imagen propia. Otros, sin embargo, se inquietan por razones distintas. Bien por "desaparecer", bien por "no estar" y reclaman audiencia como sea ("que hablen mal de uno, pero que hablen"). Algunos se alteran por "estar como no quieren". Y en este último caso la sensación de claustrofobia de sí mismo llega a ser dolorosa, especialmente porque lo que somos en el ciberespacio forma parte esencial de una de las primeras máscaras sociales que nos presenta al mundo.

\section{Políticas de la afectividad y obligatoriedad del vínculo online}

Quisiera que alguien mirara las bellas fotos de mi dedo meñique, de mi codo o de mi clavícula izquierda, pero todos buscan mi rostro, mi cuerpo desnudo y aquellas palabras fatídicas de un día con cámaras que quiero olvidar. ${ }^{5}$ Laura Bey

Lo que obliga en el regalo recibido, intercambiado, es el hecho de que la cosa recibida no es algo inerte. ${ }^{6}$

Marcel Mauss 
Cada mañana recibo: 9 mensajes de spam y ofertas comerciales, 4 emails relativos a mi trabajo temporal, 1 saludo de un viejo amigo; 3 de personas que no conozco y me piden amistad, 2 de personas que me convocan a reuniones, revoluciones y eventos, 4 de personas que diariamente me informan de sus cosas y gustos, 3 notificaciones pendientes. Maldito dedo. Cuanto más clickeo, más mensajes circulan y más obligaciones tengo. Adoro recibir cartas. ${ }^{7}$

Laura Bey

Recibir un mensaje es probablemente una de las experiencias que más disfruto si ese mensaje está dirigido a mí y escrito por un humano y no por un robot. Hay en esta filia, claro está, pasado vivido que ubica el teléfono como vehículo de las malas noticias, las que requieren urgencia, y a la palabra escrita como medio para compartir ideas, proyectos o afectos, a menudo inesperados.

Estas cartas que hoy llamamos mensajes y que gustan, lo hacen si son personales, afectivas, de alguien que me escribe a mí y no a un genérico, alguien que escribe para compartir o para arropar, lo que las palabras puedan. Me gusta además por su infrecuencia, porque la mayoría de mensajes que llegan a mi buzón están enviados por robots que me molestan y entretienen con publicidad, spam e invitaciones que no he pedido. Otros firmados por humanos parecieran de robots, y se camuflan con un saludo personal tras el que sigue un mensaje genérico o disfrazado de personal pero extraído de una nota tipo. Pocas veces quien escribe me conoce o sabe realmente mi nombre, o que respondo a ese, o a otros nombres. Y yo en mi cuarto propio conectado con mi existencia cuestionada por la interacción posible de los otros, necesito saber que existo y que alguien sabe que esa expresión con mis iniciales y marcada con una @ tiene acceso directo a mis ojos, que yo estoy detrás o adjunta. Es decir, sola gran parte del tiempo tras la pantalla preciso ese otro tipo de afecto no limitado a un I like your image.

Entre los distintos mensajes que recibo y que me importan, ocurre que después de recibirlos suele aparecer un malestar que imita ser un leve dolor de estómago, sin serlo. Es un malestar que me recuerda que no he devuelto la respuesta prometida, que debo enviar el artículo, que no he terminado ese favor comprometido que resiste sin descolgarse en tareas pendientes... Y sin menospreciar la ansiedad que todo ello me 
genera, no deja de cautivarme su afán por agarrarse a mi memoria y punzar para recordar. Pese a tener muchos mensajes sin respuesta y cosas pendientes que con distinta intensidad me obligan, sólo algunos me generan la sensación de deuda abierta; sólo algunos tratan realmente de cosas, afectos y vínculos que me importan.

Como saltándome al paso, este pensamiento me acompaña queriendo escribir sobre creación de valor y lazo social (afectivo, político...) en una sociedad conectada. Y en un primer balance quisiera hacerlo preguntándome por los vínculos sin la exigencia del medio o, cuando menos, desde su no presencia explícita (off/online); pensando en las alianzas que nos mueven en nuestras vidas cotidianas, habitando el mundo material y en él también la red. La pregunta sería por tanto hacia aquellas relaciones humanas que logran movilizarnos, hacernos creer que algo en esas personas a las que nos vinculan se nos hace propio y nos importa. Es decir, que nos permite pasar del yo al nosotros. Y creo que esta reflexión importa pues, ¿no es acaso en el tipo de vínculo y no en la mera posibilidad de estar conectados donde radica la verdadera potencia política de una red?

Verán que esta cuestión hablándonos de relaciones, obligaciones y deudas con los otros, trata realmente de política, afectos e identidad, del poder ser a través de los vínculos que marcan el dar y el devolver en nuestras relaciones. ¿Acaso ese juego de intercambios que habla del yo y del nosotros valiéndose de lazos sociales, difiere en su potencia política en el contexto Internet? ¿Condicionaría ésta (la red) en sus distintas máscaras, determinados tipos de alianza y obligaciones con los otros?

A priori observo cómo en Internet el incontenible número de voces que se pronuncian, la pluralidad de intercambios digitales, de contenidos disponibles y mensajes recibidos imposibilitan una devolución o respuesta personalizada a todos aquellos que nos reclaman atención o con los que interactuamos. Las razones oscilan: muchos de nuestros remitentes son desconocidos; a veces se limitan a un correo o dato personal apropiado por aplicaciones o personas y puesto en circulación; en ocasiones ni siquiera son personas sino robots que generan apariencia de discurso y de sujeto; y, en todo caso, su exceso limita la posibilidad de intervención personalizada.

Sin embargo, la red y sus industrias nos muestran una imagen de alta sociabilidad, de posibilidad de conexión casi infinita e inmediata con los otros. Del paso casi instantáneo y ligero del 
yo a potenciales comunidades multitudinarias, sin necesaria mediación reflexiva, a golpe de mecha, post, tweet, invitación o envío masivo. Pero no pasa por alto cómo esta disponibilidad mengua su potencia al eclipsar con cantidad y contexto la falta de profundidad de una forma de vinculación liviana por excesiva; una vinculación rápida que no precisa más compromiso que la sintonía y el golpe de mano (send) desde un cuarto propio conectado o desde cualquiera de las variantes de conexión que el espacio público-privado online nos permite hoy, donde podemos ver y hacer sin que necesariamente medie una contrapartida o sin que ésta nos obligue demasiado.

Esta posibilidad de vinculación rápida parece diluir la capacidad de atención en distracción por plétora de estímulo. Una vinculación que cada vez más surge premeditada desde las dinámicas mercadotécnicas y capitalistas de "gestión afectiva" 8 en Internet. No cabe olvidar que gran parte de los servicios que caracterizan estas dinámicas se apoyan en la gestión y comercialización del tiempo (tiempo para relacionarnos y consumir "a los otros", para conectarnos y usar mientras producimos y volvemos...). Estos servicios están orientados a garantizar la permanencia de quienes los usan, amplificando el número de vínculos, el número de minutos dedicados a nuestros vínculos y, por tanto, el número de minutos de uso del espacio que nos acoge y nos reclama volver.

Al yo se le seduce y atrapa haciéndole partícipe de los espacios que genera con su propia experiencia vital, comprometiéndole en un espacio que le identifica simbólicamente, que considera propio y, ¿cómo no volver a la casa digital, al lugar donde todos saben tu nombre?, donde una voz femenina pareciera decir: "Bienvenidx a tu red social. Aquí reivindicamos -suavementemás de ti enlazándote con otras personas que seguro conoces, o que conocen los que te conocen; personas que saben cómo te llamas, qué haces y qué te gusta" (e insistirá), "personas que saben cómo te llamas" 9 . No es poca cosa la interacción constante que se estimula en estas redes a cambio de vínculos amables con otras personas, convirtiendo una tendencia en una necesidad comunitaria de época: "ser" en el mundo construyendo y habitando redes sociales. Tener miles de contactos y amigos (porque no puede haber mejor marca comercial que lo enmascarado con amistad y afecto) y paralela y significativamente "ser tenido por tu red". (ZAFRA, 2015b). 
Pero también al yo se le anima a compartir su archivo vital como guiño al otro, haciéndonos recordar aquella anécdota de Roland Barthes en la que insinuaba cómo basta con enseñar nuestras fotos a un extraño para generar un vínculo amable con nuestro interlocutor, que rápidamente devolverá el gesto mostrando también sus fotos: "Mira. Aquí mi hija, aquí mi sobrino, aquí yo...". Como respuesta, el gesto similar del extraño y en él, instantáneamente, un vínculo suave, ni siquiera un afecto, más una suerte de empatía o comprensión, por la que también compartirá desde su cartera o su teléfono móvil esas imágenes personales de aquellos a los que quiere. Como primer nivel de alianza humana que ayuda a confiar y a sintonizar con los otros.

\section{Devenir online de los vínculos afectivos y políticos en marcos capitalistas y en crisis}

No cabría olvidar la cuestión del contexto más amplio donde opera este intercambio y donde actúa Internet, el hecho de que los cambios en el estatuto de la visualidad y del sujeto conectado acontecen en un marco capitalista y propio de la crisis de principios de siglo. Un marco homogeneizador en tanto globalizador que pasa justa, y paradójicamente, por generar aspiraciones superficiales de "diferenciación" que terminan "igualándonos" a todos en dicha superficialidad. Y lo hacen a partir de las "nuevas necesidades" que nos generan las últimas tendencias tecnológicas (su filosofía de obsolescencia demandante de actualización constante). Estas aspiraciones atienden a reclamaciones estetizadoras de construcción de universos visuales propios, autobiográficos, identidades sustentadas en imágenes capturadas y en realidad vivida, es decir mundo pasado y presente continuo.

Y de vuelta a los vínculos que la red favorece, no pasa desapercibido que el marco de convivencia contemporánea tienda a caracterizarse por el individualismo propio de una sociedad capitalista singularmente competitiva. Sociedad que en lo visual recuerda que frente al excedente que la caracteriza se posiciona la escasez de los primeros puestos, los que logran más ojos y más vida (visual). Pudiera ser entonces que la competencia que caracteriza la necesidad de un posicionamiento del yo real entre la maraña de yoes digitales que quieren ser visibilizados online describiera, al menos parcialmente, esta lucha del ser visto como manera de existir en Internet, como pulsión a la que nos enfrentamos cotidianamente como sujetos conectados. 
Habría, no obstante, que observar en este marco, cómo los más jóvenes se han posicionado uniéndose suavemente por lazos casi siempre afectivos y derivados de la edad. Y cómo, de manera general en los conectados los vínculos han sido cambiantes pero ligeros, derivados de compartir aficiones, proyectos o intereses temporales. Vínculos que en todo caso han reforzado identidades alejadas de viejos dogmas y fundamentalismos, capaces de definirse de varias maneras a la vez para al poco cambiar. Y aquí se advierte una potencia de resistencia que no cabe desestimar. No olvidemos que por mucho tiempo los sujetos se han rebelado frente a los vínculos fuertes como aquéllos que fácilmente nos llevaban al conflicto, a las guerras y a los dogmatismos.

Las identidades fuertes no han caracterizado ni la época reciente ni estas formas de unión líquida en las redes (sobre todo redes sociales); cuando menos, no en un sentido de lo común acreditado por compartir vínculos propios de un compromiso ideológico, político o moral. De hecho, en la última década de socialización de Internet previa a la crisis mundial, la primacía ha sido más bien de vínculos sustentados en la afición, la amistad, la edad y la sintonía de proyectos que nos unen sólo un tiempo.

Pero algo resulta llamativo. Otras formas de escasez y desigualdad, esta vez materiales, están transformando las cosas. Así, tras los recientes (y aún muy vivos) cambios sociales y económicos derivados de la crisis mundial cabría preguntarse si la nueva solidaridad emanada de la precariedad y la injusticia social, no está gestando "otro tipo de vínculo" afectivo-ético-político, aún indefinido pero más fuerte. Es decir, si la realidad no pudiera vengarse ahora de la hegemonía estetizadora ${ }^{10}$ favorecida por el capitalismo pero también por las redes (en tanto mediadoras de materialidad interfaceada), transformándola en potencia política de un nuevo "nosotros" o algo que se le parece. La impresión es que seguirían siendo espacios no definidos por un sentido de adscripción y pertenencia a una colectividad, sino por la "co-presencia" en un espacio compartido; de manera que quizá debiéramos hablar en lugar de movimientos sociales, de una suerte de transformación de "lo social" tan plural como fluida, y que podría ayudarnos a valorar la novedad de las recientes movilizaciones colectivas con las redes sociales como escenario preferente y con la crisis económica como mecha.

La instantánea nos devuelve hoy un mundo donde la crisis hace mutar el escenario que aquí comparto. Un mundo im- 
pactado, donde las generaciones más jóvenes de conectados han crecido en un entorno post-ideologizado, post-politizado, y donde confluyen diversidad de procedencias, géneros, edades y culturas, con fácil acceso a la información. Multitudes a las que la crisis ha hecho bifurcar más que nunca el sentido de lo político hacia una noción en auge de "lo común". De un lado, el rechazo a la clase política y, de otro, la articulación de nuevos lazos de distinto gradiente afectivo que hablan más de afinidades que de identidades, y de espíritus de "disconformidad" e indignación antes que de espíritus revolucionarios en un sentido clásico.

Las contradicciones perviven, pues los vínculos que les unen grupalmente son también vínculos políticos en el sentido de solidaridad colectiva e implicación en lo público, pero presumen sin embargo de estar desactivados política e ideológicamente como si quisieran diferir de una idea de lo político que les daña. Creo que este gesto pretende hacer frente (por rechazo) a las clásicas formas de cohesión de viejas colectividades trasnochadas y cosidas por dogmas, que sentimos que ya no nos identifican, que de ellas queremos también diferir. Que de querer ser, queremos ser algo "distinto", puede que todavía indefinido, gestándose, en proceso, otra cosa, donde lo político estaría de otra manera. No habría por tanto que sentenciar, anulando, la potencia de esta transformación por adelantado, comparándola con el pasado para limitarla bajo un concepto predefinido de "lo político", sino que tendríamos más bien que mirarla con lentes que también están cambiando, que saben que están cambiando. Por ello, antes de dar por agotada su potencia y sucumbir a los condicionantes y señas de época, cabría tolerar el tiempo que vivimos como un periodo de reflexión y mutación de los vínculos afectivos y políticos en algo distinto, intervenido indudablemente por la construcción colectiva de lo común y de lo que importa.

NOTAS

1. Laura Bey, Mi vida en la primera IP, (obra artística), parcialmente publicada en 2010 y accesible en: <http://2-red.net/mividaenlaprimeraip > entre 2010 y 2012.

2. Roland Barthes, La cámara lúcida. Nota sobre la fotografía, Paidós, Barcelona, 2010, p. 46.

3. En el desarrollo del concepto biopoder que realiza Michel Foucault en el volumen de Historia de la sexualidad I, La voluntad de saber, incide en cómo el poder funciona de una parte como disciplina y de otra como gestión y control. Esta pareja disciplina y gestión puede considerarse indispensable para el desarrollo del capitalismo contemporáneo. Ver: Michel Foucault, Historia 
de la sexualidad, 1: La voluntad de saber, Siglo XXI, 2005. Sin embargo, y tal como sugiere Deleuze, el paso de las sociedades disciplinarias a las sociedades de control, operaría más desde un poder que se difunde casi capilarmente a través de las tecnologías facilitando el control de las personas, del que en este texto deduzco la configuración de nuevas formas de disciplina (como principio de control de la producción de discurso y estructura-red) y autogestión en las redes, formas de las que se alimenta el nuevo capitalismo. Ver: Gilles Deleuze, "Postcriptum sobre las sociedades de control”. En Conversaciones 1972-1994, Editorial Pre-textos, Valencia, 1999.

4. Roland Barthes, La cámara lúcida. Nota sobre la fotografía, op. cit., p. 122.

5. Laura Bey, Mi vida en la primera IP, op. cit.

6. Marcel Mauss, Ensayo sobre el don: Forma y función del intercambio en las sociedades arcaicas, Ensayo sobre el don. Forma y función del intercambio en las sociedades arcaicas, Katz, Madrid, 2009, p. 88.

7. Laura Bey, Mi vida en la primera IP, op. cit.

8. El término afectividad en relación al capitalismo y trabajo afectivo no se emplea aquí en el sentido dado por los estudios sobre economía afectiva desde la Antropología Económica y los Estudios de Género, sino que se nutre en este texto de referencias provenientes de Lazzarato (1996), Knowbotic Research en Io_Lavoro Inmateriale (http://aleph-arts.org/io_lavoro/), y especialmente de Michael Hardt en sus ensayos sobre Affective Labor (1999), así como de los trabajos posteriormente desarrollados por Juan Martín Prada en sus ensayos sobre Internet y economías de la afectividad (2006 y 2012).

9. Laura Bey, Mi vida en la primera IP, op. cit.

10. El término estetización es usado aquí como proceso de acentuación o reducción a la imagen propio de Internet y de su entidad como mediador intersubjetivo y como tal apoyado en una lógica de interfaz. En un sentido crítico apunta además a la posible banalización que se desprende de la estetización cuando ésta es reducida a su proceso exclusivamente epidérmico, que en tanto acaparador del tiempo entraría en conflicto con la profundización y toma de conciencia que presuponemos a un vínculo político.

\section{Referencias}

BARTHES, Roland. La cámara lúcida. Nota sobre la fotografía. Barcelona: Paidós, 2010.

BAUMAN, Zygmunt. Miedo líquido. La sociedad contemporánea y sus temores. Barcelona: Paidós, 2007.

BENJAMIN, Walter. Libro de los Pasajes. Madrid: Akal, 2005. BEY, Laura. Mi vida en la primera IP, (obra artística), parcialmente publicada en 2010 y accesible en: <http://2-red.net/ mividaenlaprimeraip $>$ entre 2010 y 2012.

BLONDEAU, O., VERCELLONE, C., CORSANI, A., RULLANI E. y otros. Capitalismo cognitivo, propiedad intelectual y creación colectiva. Madrid: Traficantes de sueños, 2004.

BREA, José Luis. Cultura Ram: Mutaciones de la cultura en la era de la distribución electrónica. Barcelona: Gedisa, 2007.

CANCLINI, Néstor García. Diferentes, desiguales, desconectados. Barcelona: Gedisa, 2004. 
- Google es más poderoso que las cadenas de tv o las discográficas. Revista de Cultura Ñ. Tecnología y Comunicación, 2011. Recuperado de <http://www.revistaenie.clarin.com/>.

. La sociedad sin relato: antropología y estética de la inminencia. Madrid: Katz, 2011.

DEBRAY, Régis. Vida y muerte de la imagen. Historia de la mirada en Occidente. Barcelona: Paidós, 1995.

DELEUZE, Gilles. "Postcriptum sobre las sociedades de control". In: Conversaciones 1972-1994. Valencia: Pre-textos, 1999.

ECO, Umberto. Dando a cambio nuestra privacidad. Sociólogos, 2014. Recuperado de: <http://ssociologos.com/2014/o8/o4/ umberto-eco-dando-cambio-nuestra-privacidad/>.

FOUCAULT, Michel. Microfísica del Poder. Madrid: La Piqueta, 1980.

GIDDENS, Anthony. Modernidad e identidad del yo: El yo y la sociedad en la época contemporánea. Madrid: Península, 2000.

GUATTARI, Félix. Plan sobre el planeta. Capitalismo mundial integrado y revoluciones moleculares. Madrid: Traficantes de Sueños, 2004.

GUIGOU, L. N. El ojo, la mirada: Representación e imagen en las trazas de la Antropología Visual. Diverso Revista de Antropología Social, 4, 2001, p. 123-134.

HARAWAY, D. Ciencia, Ciborgs y mujeres. La reinvención de la naturaleza. Madrid: Cátedra, 1995.

HARDT, M. Affective Labor. In: Boundary 2. Vol. 26, №. 2, Summer 1999.

LOVINK, G. Fibra oscura. Rastreando la cultura crítica de Internet. Madrid: Tecnos, 2004.

MARTÍN PRADA, J.'La creatividad de la multitud conectada y el sentido del arte en el contexto de la Web 2.o", Estudios visuales, 5, 2008, 66-79.

. Economies of affectivity, Multitudes. Revue politique, artistique, philosophique. Recuperado de <http:// www.multitudes.net/Economies-of-affectivity/>, 2007.

MAUSS, M. Ensayo sobre el don: Forma y función del intercambio en las sociedades arcaicas, Ensayo sobre el don. Forma y función del intercambio en las sociedades arcaicas. Madrid: Katz, 2009.

NEGRI, T. y HARDT, M. Multitud. Barcelona: Debate, 2004. VIRNO, P. Gramática de la multitud. Para un análisis de las formas de vida contemporáneas. Madrid: Traficantes de sueños, 2003. 
ZAFRA, R. Un cuarto propio conectado. Madrid: Fórcola, 2010. (2015), Ojos y capital. Bilbao: Consonni. (2015b). Sujeto y red: potencia y limitación política del (des)hacer los cuerpos online*. Caderno Pagu, Campinas, n. 44, p. 13-30, jun.

ŽIŽEK, S. Pedir lo imposible. Madrid: Akal, 2014.

Aceito em: 10/01/16

Recebido em: 12/05/16

\author{
REMEDIOS ZAFRA \\ www.remedioszafra.net \\ Doctora y licenciada en Arte, licenciada en Antropología Social y \\ Cultural, Doctorado en Filosofía Política y Master Internacional \\ en Creatividad. Orienta su trabajo ensayístico y de investigación \\ al estudio crítico de la cultura contemporánea, el feminismo y los \\ estudios sobre identidad en las redes. Actualmente es Profesora \\ Titular de la Universidad de Sevilla.
}

